\title{
Reaction of Commercial Soft Red Winter Wheat Cultivars to Stagonospora nodorum in the Greenhouse and Field
}

Jessica S. Engle, Graduate Research Associate, and Patrick E. Lipps, Professor, Department of Plant Pathology; and Richard J. Minyo, Jr., Research Associate, Department of Horticulture and Crop Science, The Ohio State University, Wooster 44691

\begin{abstract}
Engle, J. S., Lipps, P. E., and Minyo, R. J., Jr. 2006. Reaction of commercial soft red winter wheat cultivars to Stagonospora nodorum in the greenhouse and field. Plant Dis. 90:576-582.

Thirteen cultivars were evaluated in the greenhouse and field for reaction to Stagonospora nodorum leaf and glume blotch. Coker 9663 exhibited consistent resistance across both greenhouse and field tests. In field plots, all cultivars tested had relatively high percentages of $S$. nodorum in harvested seed. Strong correlations between reactions from greenhouse and inoculated plots indicated that resistant and susceptible genotypes could be identified using either procedure. The amount of $S$. nodorum resistance expressed depended on the host organ assessed, but Coker 9663, and OH708 in inoculated field plots, had both leaf and glume blotch resistance. Cultivars reacted similarly in inoculated and naturally infested plots based on mean leaf or glume blotch severity, whereas severity was inconsistent between the greenhouse and naturally infested plots. Results indicated that leaf and glume blotch resistance could be identified in naturally infested plots in epidemic years, but that cultivar reactions should be confirmed in inoculated plots or greenhouse tests due to possible interference from other leaf blotch pathogens.
\end{abstract}

Additional keywords: Phaeosphaeria nodorum, Triticum aestivum

The wheat (Triticum aestivum L.) pathogen Stagonospora nodorum (Berk.) (Castellani and E. G. Germano) (teleomorph: Phaeosphaeria nodorum (E. Müller (Hedjaroude))) causes Stagonospora leaf and glume blotch (24). This disease became one of the major leafspotting diseases in Indiana during the late 1980 s, coinciding with an increase in conservation tillage (28). Stagonospora leaf and glume blotch affects grain quality, and yield may be reduced as the result of lower test weights $(13,22)$. Foliar disease reduces photosynthetic area of the flag leaf and decreases the amount of carbohydrates available for seed fill (11). The milling quality of grain may be reduced, because infection of the developing seed causes shriveling and reduced flour yield (9).

$S$. nodorum can infect wheat plants at any stage of development (30) and it has many grass host species (12). Current control of this disease is achieved through cultural practices, fungicide application, and the use of resistant cultivars $(17,19)$. Primary cultural management practices include crop rotation and burying infested residue by tillage to reduce the survival of

Corresponding author: P. E. Lipps

E-mail: lipps.1@osu.edu

Accepted for publication 3 December 2005.

DOI: 10.1094/PD-90-0576

(C) 2006 The American Phytopathological Society the fungus from one crop to the next $(17,19)$. Control of the fungus on seed is achieved through fungicide seed treatments to prevent the seedling phase of the disease that may affect epidemic development during later crop growth stages $(17,19,26)$. Application of foliar fungicides can reduce yield loss to Stagonospora leaf blotch in epidemic years, but the cost can be economically prohibitive when the price of wheat is low $(15,17,19,30)$. Moderately resistant cultivars are available, but there currently are few cultivars with high levels of resistance to this pathogen (15).

Resistance to $S$. nodorum is quantitatively inherited $(7,20,21,24,25)$. Resistance reactions at different stages of wheat development appear to be independent and not highly correlated (12). Weakly aggressive isolates of $S$. nodorum have a limited ability to cause disease and, therefore, do not distinguish wheat genotypes for $S$. nodorum resistance (25). Highly aggressive isolates allow better estimation of reaction. To avoid confounding effects of plant height in greenhouse resistance studies, it is recommended to evaluate resistance to $S$. nodorum by inoculating plants at the same physiological stage regardless of age in days (6). Previous researchers have found that, in general, winter wheat cultivars have higher levels of resistance than spring wheat cultivars in both field and greenhouse studies (25).

In general, glume blotch reactions of cultivars have correlated more closely between greenhouse and field studies than leaf blotch reactions (31). Most resistance components measured in controlled environments, such as incubation period and percent leaf area affected, have not correlated consistently with field disease severity $(10,25)$. Examining these components can differentiate the most susceptible genotypes from moderately resistant genotypes in greenhouse and growth-chamber studies $(10,20,25)$. Studies examining segregating populations have determined the potential for early generation selection for Stagonospora glume blotch resistance $(7,20)$. A confounding variable in field studies has been mixed infection with other leaf-spotting pathogens, such as Pyrenophora tritici-repentis (tan spot) and Septoria tritici (Septoria blotch), that produce lesions similar to those of Stagonospora nodorum $(5,16)$. Evaluating resistance response in the field also may be complicated by variation in environment, amount of natural inoculum, and competition between pathogens for healthy tissue to infect and colonize.

Determining the resistance reaction of cultivars and lines to Stagonospora leaf blotch requires multiple year and location studies due to the quantitative nature of resistance and environmental effects. Although research plots can be managed to create disease epidemics for a small set of test cultivars, large-scale cultivar performance trials at multiple locations across a state are expensive and difficult to maintain. Regardless, producers depend on state-wide performance trials to obtain relative yield performance and multiple disease reaction evaluations of cultivars for specific areas of a state. During years of Stagonospora leaf and glume blotch epidemics, producers will examine cultivar disease reactions in the performance trial reports to select resistant cultivars that perform well in their area of the state.

The objective of this study was to determine the leaf blotch and glume blotch reactions of 13 commercially grown soft red winter wheat cultivars to isolates of $S$. nodorum obtained in Ohio. A secondary objective was to determine whether cultivars responded similarly to inoculation in the greenhouse, under natural infestations in field plots, and in inoculated field plots.

\section{MATERIALS AND METHODS}

Cultivar selection. Thirteen soft red winter wheat cultivars were chosen based 
on field ratings for Stagonospora leaf blotch over 3 years (Table 1). The cultivars and lines had reactions ranging from moderately resistant to susceptible, but some had different reactions across years. To help obtain diversity, the cultivars represented genotypes from public (Freedom, Hopewell, Patterson, Roane, and Sisson), and private (Honey, Bravo, Bouillon, Coker 9025, Coker 9474, Coker 9663, AGRA GR535, and Patton) wheatbreeding programs. Seed of these cultivars were available for commercial planting in Ohio. Two check cultivars with known reactions, AGRA GR863 (susceptible) and OH708 (resistant), were included in inoculated field plots, but not in the greenhouse or naturally infested field plots.

Greenhouse experiments. Plant growth. Seed of the 13 commercial cultivars was obtained from seed companies and stored at $3.5^{\circ} \mathrm{C}$. In fall 2002 , seed were germinated on germination paper in the laboratory and, after 1 week, healthy seedlings were placed into trays of autoclaved Wooster silt-loam soil and maintained in a $3.5^{\circ} \mathrm{C}$ chamber for 65 days for vernalization. Each tray was treated with granular mefenoxam (Ridomil, $1 \mathrm{~g}$ a.i./tray; Novartis, Inc., Greensboro, NC), fertilized with pellets of Triple 14 Osmocote (N 14\%, P 14\%, K 14\%; 12 g/tray; Scotts, Inc., Marysville, $\mathrm{OH})$. Lights in the chamber were set to provide an 8-h photoperiod and trays were watered as needed.

After the vernalization period, 30 plants of each cultivar were transplanted individually into $12.7-\mathrm{cm}$-diameter pots containing 3 M Metro Mix (Conrad Fafard, Inc., Agawam, MA). Each individual plant in a pot was considered a replication. A repetition was considered an experimental repeat. Four experimental repeats were separated over time with approximately 1 month between planting dates. For each repetition, 20 plants of each cultivar were inoculated and 10 plants were used as noninoculated controls. Leaves of plants were clipped to approximately $5 \mathrm{~cm}$ above the soil line 2 days after transplanting and pots were arranged randomly on benches in the greenhouse. The greenhouses averaged $20.8^{\circ} \mathrm{C}$ during the day and $19.2^{\circ} \mathrm{C}$ at night, with a 12-h light period supplemented by one $1,000-\mathrm{W}$ metal halide lamp and four 1,000-W high-pressure sodium lights in each $44.5-\mathrm{m}^{2}$ greenhouse. Through the course of the experiment, plants were loosely tied to $30-$ to $60-\mathrm{cm}$ long bamboo stakes for support.

Pots were fertilized weekly with $100 \mathrm{ml}$ of Triple 20 Peter's fertilizer solution (N $20 \%$, P 20\%, K 20\%; 4.8 g/liter of water; Scotts, Inc.). For insect control, plants were sprayed weekly with S-kinoprene (Enstar, $0.01 \mathrm{~g}$ a.i./liter of water; Wellmark, Bensenville, IL) or abamectin (Avid, $0.01 \mathrm{~g}$ a.i./liter of water; Syngenta Crop Protection, Inc., Greensboro, NC). Applications of triadimefon (Bayleton, $2.2 \mathrm{~g}$ a.i./liter water; Bayer Corp., Kansas City, MO) were applied 2 weeks after transplanting into pots and 2 weeks thereafter for control of powdery mildew (Blumeria graminis f. sp. tritici (DC.) E. O. Speer) for the first 4 weeks after vernalization. The last application of fungicide was at least 4 weeks prior to the first inoculation. No interaction of the fungicide on disease development was observed.

Inoculum production and inoculation. Plants were inoculated when the main tiller of each plant had a fully emerged flag leaf (Feekes growth stage 9) (14). Inoculations were made by atomizing a $1 \times 10^{6}$ pynidiospore/ml suspension on each fully expanded flag leaf to the point of run-off. Bulk suspensions were made from 10 isolates of $S$. nodorum obtained from wheat leaves collected at different locations in Ohio in 2002. Isolates were grown on V8 agar modified with streptomycin sulfate (Sigma-Aldrich, St. Louis) at $50 \mathrm{mg} / \mathrm{liter}$. The agar cultures from 8-cm-diameter petri dishes of each isolate were inverted onto four layers of cheese cloth, dipped into a beaker containing $100 \mathrm{ml}$ of tap water, and strained to obtain pycnidiospores. No attempt was made to have equal numbers of pycnidiospores from the individual isolates. Suspensions were enumerated using a hemacytometer according to the protocol for counting small spores (29).

After inoculation, plants were placed into a mist chamber made of a 2.3-by-1.4by-1.0-m PVC skeleton enclosed by polyethylene sheeting with adjustable sides. An air atomizer with a fluid nozzle (\#2850 SS,

Table 1. Field reaction of 13 soft red winter wheat cultivars to Stagonospora nodorum during 2000 and 2001 in Ohio and 2002 in Pennsylvania

\begin{tabular}{|c|c|c|c|c|}
\hline \multirow[b]{3}{*}{ Cultivar } & \multicolumn{4}{|c|}{ Blotch rating ${ }^{u}$} \\
\hline & \multicolumn{3}{|c|}{ Leaf } & \multirow{2}{*}{$\frac{\text { Glume }}{2000 \text { Ohio }^{y}}$} \\
\hline & 2000 Ohio $^{v}$ & 2001 Ohio $^{w}$ & 2002 Penn. ${ }^{x}$ & \\
\hline AGRA GR535 & 7.0 & 7.0 & $\ldots$ & 15.0 \\
\hline Bouillon & 5.0 & 7.3 & $\ldots$ & 6.0 \\
\hline Bravo & 8.0 & 6.0 & 5.0 & 17.0 \\
\hline Coker 9025 & $\ldots$ & 5.0 & 4.7 & $\ldots$ \\
\hline Coker 9474 & 3.0 & 8.0 & 6.0 & 6.0 \\
\hline Coker 9663 & 2.0 & 3.3 & 5.0 & 1.0 \\
\hline Freedom & 7.0 & 6.3 & 3.3 & 7.0 \\
\hline Honey & 4.0 & 7.3 & 4.7 & 0.0 \\
\hline Hopewell & 3.0 & 7.0 & 5.0 & 2.0 \\
\hline Patterson & 8.0 & 7.0 & $\ldots$ & 23.0 \\
\hline Patton & 6.0 & 7.0 & 3.7 & 12.0 \\
\hline Roane & 2.0 & 6.3 & 4.3 & 1.0 \\
\hline Sisson & $\ldots$ & 6.7 & 4.3 & $\ldots$ \\
\hline Total lines $\mathrm{z}$ & 53 & 43 & 36 & 53 \\
\hline High & 10.0 & 9.7 & 7.3 & 28.0 \\
\hline Mean & 6.0 & 7.4 & 4.8 & 12.0 \\
\hline Low & 2.0 & 3.3 & 2.7 & 0.0 \\
\hline Least significant difference & 2.0 & 1.5 & $\ldots$ & 11.0 \\
\hline
\end{tabular}

u ... = Cultivar not included in tested lines.

$\checkmark$ Visual scale of 0 (resistant) to 10 (susceptible) rated on 8 June 2000 in Wayne County, OH (1).

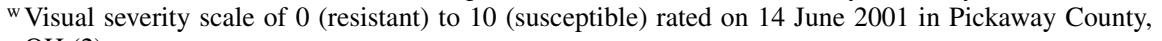
$\mathrm{OH}(2)$.

${ }^{\mathrm{x}}$ Visual severity scale of 0 (resistant) to 10 (susceptible) from one Pennsylvania field site (23).

y Percent glume area affected rated on 8 June 2000 in Wayne County, OH (1).

${ }^{\mathrm{z}}$ Total number of cultivars entered in tests.
$0.56 \mathrm{~kg} / \mathrm{cm}^{3}$ of water; Spraying Systems, Cokane, WA) and an air nozzle (\#70, Co water for 30 s every 3 min above a polyethylene canopy over the plants. The temperature in pexist chanber was maintained at approximately $22^{\circ} \mathrm{C}$ and the relative humidity was approximately $100 \%$. Inoculated for $48 \mathrm{~h}$. Control plants were placed in the opposite end of the mist chamber from the noculated plants.

After $48 \mathrm{~h}$ in the mist chamber, plants were returned to the greenhouse. Care was trol plants and the inoculated plants. Plants
of different cultivars were arranged randomly on greenhouse benches by inoculation date. The flag leaves were visually assessed for percent diseased leaf area 7 , 14,21 , and 28 days after inoculation.

Spikes were inoculated when they had fully emerged on the main tiller of each plant (Feekes stage 10.3) (14). Plants were pere $\times 10^{6}$ pycnidiospores $/ \mathrm{ml}$ was atomized onto the fully emerged spike until the point of run-off. Previously inoculated flag leaves were protected by placing a plastic bag over them during inoculation. After of the spikes, a clear plastic secured using a twist tie and reture and the greenhouse. Plants were placed randomly on greenhouse benches according to spike inoculation date rather then leaf inoculation date. After a 48-h incubation period, the plastic bags were removed. the con- 
Spikes were assessed visually for percent diseased glume area 7, 14, 21, and 28 days after inoculation.

Field experiments. Inoculated plots. Seed of the 13 cultivars and the $S$. nodorum-susceptible check AGRA GR863 were planted in inoculated field plots in 2002 and 2003. In 2003, the resistant check $\mathrm{OH} 708$ also was included in the inoculated field plots. The experiments were arranged as a randomized complete block with three replicate blocks. One field plot was planted in Wayne County, Ohio, on 17 October 2002. In 2003, field plots were established in Wayne County and Wood County, Ohio, on 10 October and 9 October, respectively. Approximately $3 \mathrm{~g}$ of seed of each cultivar were planted into each hill plot and hill plots were spaced $0.46 \mathrm{~m}$ apart in fields that previously had been cropped with soybean. The fields were prepared by moldboard plowing, and a fall $(22.8 \mathrm{~kg} / \mathrm{ha})$ and spring $(56.8 \mathrm{~kg} / \mathrm{ha})$ application of nitrogen was made. Three rows of AGRA GR863 were planted between hill plots, using a small plot drill, to promote spread of inoculum.

Field inoculum and inoculations. Plots were inoculated in two ways. First, wheat straw infested with $S$. nodorum from the previous year was spread on the ground surface in the spring before flag leaf emergence. The plots were inoculated again by spraying a $1 \times 10^{6}$ pycnidiospores $/ \mathrm{ml}$ of water suspension when $50 \%$ of the plants in the plot had fully emerged flag leaves (Feekes stage 9) (14). The suspension was applied with a hand-pump sprayer until all of the flag leaves had a fine layer of suspension covering the leaf. The same composite of 10 isolates of $S$. nodorum used in greenhouse experiments was used to spray inoculate the field plots. After inoculation, plots were misted continuously for 3 of every $10 \mathrm{~min}$ for 7 days from 7:00 p.m. to 7:00 a.m. to maintain a high relative humidity to favor disease development. A second spray inoculation was applied when $50 \%$ of the plants in the plot had fully emerged spikes (Feekes stage 10.3) (14). Flag leaves and glumes were assessed weekly from flag leaf emergence through senescence for leaf or glume area affected. The entire hill plot was assessed visually for mean percent leaf or glume area diseased each week.

Naturally infested plots. The 13 cultivars also were planted across the state as entries in the Ohio Wheat Performance Trial during 2002 and 2003 in Crawford, Darke, Pickaway, Wayne, and Wood Counties. Each site had four completely randomized replications arranged in blocks, where a replication was a drill strip, $6.2 \mathrm{~m}$ long by $1.6 \mathrm{~m}$ wide, containing seven rows. The plots were maintained according to wheat production recommendations for Ohio and exposed only to natural inoculum $(3,4)$. The percentage of flag leaf area affected by leaf blotch of 10 randomly selected plants in the plots was assessed visually weekly from flag leaf emergence through early senescence. Likewise, the percentage of glume area affected by glume blotch was assessed visually as described above from spike emergence through early senescence. Of the five locations planted in each year, only the Pickaway County site in both years and the Wayne County site in 2002 had adequate amounts of glume blotch to evaluate cultivar reactions. Although leaf blotch severities were obtained from Wayne, Pickaway, and Darke County sites in 2002 and Wayne, Pickaway, and Crawford Counties in 2003, leaf blotch severities were adequate to detect cultivar differences only from the Pickaway and Wayne County sites.

Throughout the assessment period, samples of flag leaves were obtained from the naturally infested plots for confirmation of leaf-blotching organisms. Flag leaves were harvested during each weekly visual assessment, placed in a paper coin envelope, dried for 2 days in an exhaust fume hood in the laboratory, and stored at room temperature. To identify leaf-blotching pathogens, flag leaves were incubated in moisture chambers consisting of 9-cm-diameter Pyrex petri dishes containing 9-cmdiameter filter paper moistened with $5 \mathrm{ml}$ of water beneath a square of wire mesh that suspended a glass slide above the moistened filter paper. The glass slide had two pieces of double-sided sticky tape placed evenly on the top of the slide for adherence to leaves. This prevented the flag leaf from rolling during incubation in the moisture chamber. Visual assessment of fungal fruiting structures on incubated flag leaves were made 48 and $72 \mathrm{~h}$ after placing the leaf sample in the moisture chamber.

Seed infestation. At the end of the 2002 and 2003 growing seasons, 0.9-kg seed samples of combine-harvested grain were obtained from naturally infested field plots at the Pickaway and Wayne County sites. Each cultivar was replicated in each of four blocks at all locations, and 100 seed from each of these replicate plots were examined for seedborne $S$. nodorum. Seed appearing to be infected by Fusarium graminearum were not selected. The seed was placed on basal oxgall medium in petri dishes (18). The area surrounding the seed was examined for fluorescence under an ultraviolet lamp (2.5 AMP; Ultra-Violet Products, Inc., San Gabriel, CA) 4 days after placing the seed in the petri dishes (18). The percentage of seed with associated fluorescence, typical of those infected by $S$. nodorum, was calculated for each seed sample.

Seed was hand harvested from the inoculated field plots in Wayne and Wood Counties. The seed was threshed using a small bundle thresher (ALMACO, Nevada, IA). Seed samples then were aspirated (Fractionating Aspirator, CFZ1 model;
Carter Day International, Inc., Minneapolis, $\mathrm{MN}$ ) to remove light-weight seed from the samples. From each of these samples, 100 random seed were used to assess the presence of seedborne $S$. nodorum. Seed from these samples were placed on basal oxgall medium plates to determine $S$. nodorum infestation and the percentage of infected seed was calculated for each sample.

In 2003, seed harvested from the inoculated field plots and naturally infested plots at Wayne and Pickaway County sites were examined for the presence of Pyrenophora tritici-repentis (Died.) Drechs. and Bipolaris sorokiniana (Sacc.) Shoemaker. In all, 105 seed from each replicate plot for each cultivar from both sites were examined. This was done by placing 21 harvested seed on moistened filter paper in each $9-\mathrm{cm}$ petri dish. The dishes were placed under the light banks previously described for fungal spore production. Petri dishes were maintained under a 12-h light period for 5 days before being examined under a dissecting microscope for the conidia and conidiophores of $P$. triticirepentis and $B$. sorokiniana.

Statistical analysis. Disease severity assessments for leaf blotch and glume blotch taken 28 days after inoculation were analyzed for studies conducted in the greenhouse. In the inoculated and naturally infested field plots, the last assessment of disease severity on flag leaves and glumes before senescence was used for analysis. The percentage of harvested seed infested with $S$. nodorum, $P$. tritici-repentis, or $B$. sorokiniana from the field plots was used for analysis. Analysis of variance (ANOVA) was conducted by means of a linear mixed model in SAS (release 8.3; SAS, Inc., Cary, NC) using the restricted maximum likelihood (REML) method of model fitting and the Satterthwaite approximation for degrees of freedom calculation (27). Wheat cultivar was considered a fixed effect and blocks a random effect. The least squares mean for disease severity was used for the pairwise comparisons of cultivars. Data from the inoculated plots in 2002 and 2003 were combined for statistical analysis by making both year and location random effect factors in the mixed model in order to increase power of the $F$ test.

\section{RESULTS}

Greenhouse experiments. Inoculation of adult plants in the greenhouse produced a maximum disease severity of $42.6 \%$ flag leaf area affected (FLAA) on Patterson and 98.5\% glume area affected (GAA) on AGRA GR535 (Table 2). Coker 9663 had the lowest FLAA (7.2\%) and GAA (26.1\%). Cultivars had significantly different least squares mean estimates of disease severity as indicated by using a mixed ANOVA model. All pairwise comparisons among cultivars were examined to deter- 
mine statistically significant differences in disease severities. Most of the intermediate cultivar groups had overlapping severity values. Only Coker 9663 and Roane had less than $10 \%$ FLAA, but did not differ significantly from the severity of FLAA on Coker 9025, Coker 9474, or Sisson. Coker 9663 and Sisson had less than 30\% GAA and this GAA severity was significantly less than that of other cultivars tested.

Field reactions. Inoculated plots. There were significant differences in the reactions of the cultivars evaluated according to pairwise comparisons for leaf blotch, glume blotch, and percent seed infested with $S$. nodorum from all field plots. The susceptible check, AGRA GR863, was most severely diseased, with a mean percentage of $77.3 \%$ FLAA (Table 3), $54.4 \%$ GAA, and a higher amount $(45.8 \%)$ of seed infested compared with most other cultivars. Coker 9663 had the least amount of FLAA $(3.6 \%)$ and GAA $(6.0 \%)$, but had similar seed infestation (33\%) levels as the other 15 cultivars tested. The resistant check, OH708, had slightly higher reactions that were not statistically different from Coker 9663 for all variables examined. Sisson had the least percentage of infested seed $(25.1 \%)$, but this amount was not significantly different from five of the other cultivars. Interestingly, Coker 9474 had intermediate FLAA (19.8\%), but high GAA $(32.5 \%)$ and the highest seed infestation $(60.1 \%)$. The cultivars in intermediate groups created from the pairwise comparisons had considerable variation for all disease parameters measured.

Naturally infested plots. In 2002, Pickaway, Wayne, and Darke County field sites had measurable amounts of Stagonospora leaf blotch, and the Pickaway and Wayne County sites had measurable amounts of glume blotch. In 2003, Pickaway, Wayne, and Crawford County field sites had measurable amounts of leaf blotch, and the Pickaway County site had measurable amounts of glume blotch. Examination of leaf blotching pathogens from field samples in 2002 indicated that over $80 \%$ of leaf samples had S. nodorum (data not presented) from all sites. In 2003, the leaf blotching pathogens were more diverse, with disease being caused by $S$. nodorum, $P$. tritici-repentis, and B. sorokiniana (data not presented) from all sites. The most prevalent pathogen $(63 \%$ of leaf samples) in 2003 plots was $S$. nodorum. Pearson's correlations coefficient between leaf and glume blotch severities across years and sites in the naturally infested plots were highly variable due to variable disease intensity. Since Wayne and Pickaway County sites had consistent measurable amounts of leaf blotch and glume blotch, these sites were used in data analysis.

Disease intensity in naturally infested plots was high enough and the range in cultivar reactions broad enough to statisti- cally evaluate the cultivars in Wayne and Pickaway Counties. Leaf blotch severities ranged from a high of 58.9\% FLAA for Patterson and Honey to a low of $19.8 \%$ FLAA for Coker 9663 (Table 4). Glume blotch severities ranged from a high of $24.1 \%$ GAA for Sisson to a low of $5.4 \%$ GAA for Bouillon. There were fewer cultivars represented in the intermediate reaction groups for both leaf blotch and glume

blotch tested in naturally infested plots than in the inoculated field plots (Tables 3 and 4). The percentage of infested seed was greatest for Patterson (47.8\%) (Table 4) and most cultivars had seed infestation amounts that were not statistically different from Coker 9025 (19.3\%) with the least seed infestation. Although the intensity of seed infestation was similar in the inoculated and naturally infested plots,

Table 2. Leaf and glume blotch reactions of commercial soft red winter wheat cultivars inoculated with a composite of 10 Stagonospora nodorum isolates in the greenhouse

\begin{tabular}{|c|c|c|c|c|}
\hline \multirow[b]{2}{*}{ Cultivar $^{x}$} & \multicolumn{2}{|c|}{ Leaf blotch } & \multicolumn{2}{|c|}{ Glume blotch } \\
\hline & Mean $^{y}$ & Group $^{z}$ & Mean ${ }^{y}$ & Group $^{\mathrm{z}}$ \\
\hline AGRA GR535 & 16.6 & $\mathrm{~cd}$ & 98.5 & $\mathrm{a}$ \\
\hline Boullion & 14.6 & $\mathrm{~cd}$ & 58.5 & $\mathrm{~d}$ \\
\hline Bravo & 24.1 & $\mathrm{~b}$ & 85.8 & $\mathrm{abc}$ \\
\hline Coker 9025 & 13.7 & cde & 59.1 & $\mathrm{~d}$ \\
\hline Coker 9474 & 11.5 & def & 72.3 & bcd \\
\hline Coker 9663 & 7.2 & ef & 26.1 & $\mathrm{e}$ \\
\hline Freedom & 17.0 & $\mathrm{c}$ & 74.6 & bcd \\
\hline Honey & 24.7 & $\mathrm{~b}$ & 89.6 & $a b$ \\
\hline Hopewell & 26.1 & $\mathrm{~b}$ & 79.9 & $a b c$ \\
\hline Patterson & 42.6 & $\mathrm{a}$ & 82.2 & $a b c$ \\
\hline Patton & 16.2 & $\mathrm{~cd}$ & 79.2 & bc \\
\hline Roane & 9.0 & ef & 68.5 & $\mathrm{~cd}$ \\
\hline Sisson & 11.4 & def & 30.8 & $\mathrm{e}$ \\
\hline Mean & 18.1 & $\ldots$ & 69.6 & $\ldots$ \\
\hline
\end{tabular}

${ }^{\mathrm{x}}$ Effect of cultivar was significant $(P<0.0001)$ using the $F$ test in a linear mixed model (with Satterthwaite approximation for degrees of freedom) for both leaf and glume blotch.

${ }^{y}$ Least squares means of percentage flag leaf or glume area affected 28 days after inoculation were approximated using restricted maximum likelihood. Means were based on four repetitions of approximately 20 replicate plants per cultivar inoculated. Uninoculated control plants $(n=10)$ were excluded from data analysis.

${ }^{\mathrm{z}}$ Groups were assigned based on pairwise comparisons of the cultivar means, based on standard error of mean differences determined in the mixed model. Means followed by the same letter are not significantly different at $P \leq 0.05$.

Table 3. Reaction of the 15 cultivars in inoculated plots in Wayne County 2003 and Wayne and Wood Counties in 2004

\begin{tabular}{|c|c|c|c|c|c|c|}
\hline \multirow[b]{2}{*}{ Cultivar $^{x}$} & \multicolumn{2}{|c|}{ Leaf blotch ${ }^{\mathrm{v}}$} & \multicolumn{2}{|c|}{ Glume blotch ${ }^{v}$} & \multicolumn{2}{|c|}{ Seed infestation ${ }^{w}$} \\
\hline & $\operatorname{Mean}^{y}$ & Group $^{z}$ & Mean' & Group $^{z}$ & Meany & Group $^{z}$ \\
\hline GR535 & 26.3 & defg & 25.7 & bcde & 42.9 & bcde \\
\hline GR863 & 77.3 & $\mathrm{a}$ & 54.4 & $\mathrm{a}$ & 45.8 & $\mathrm{bc}$ \\
\hline Bouillon & 25.6 & defg & 11.1 & efg & 43.1 & bcde \\
\hline Bravo & 34.9 & cde & 23.3 & bcdef & 40.8 & cde \\
\hline Coker 9025 & 31.3 & def & 10.3 & $\mathrm{fg}$ & 31.7 & def \\
\hline Coker 9474 & 19.8 & defg & 32.5 & $\mathrm{bc}$ & 60.1 & $\mathrm{a}$ \\
\hline Coker 9663 & 3.6 & $\mathrm{~g}$ & 6.0 & $\mathrm{~g}$ & 33.0 & cdef \\
\hline Freedom & 38.1 & cde & 15.9 & defg & 31.0 & def \\
\hline Honey & 62.2 & $a b$ & 20.4 & cdefg & 30.7 & ef \\
\hline Hopewell & 42.0 & bcd & 18.4 & cdefg & 40.6 & cde \\
\hline OH708 & 6.7 & $\mathrm{fg}$ & 10.8 & efg & 36.5 & cdef \\
\hline Patterson & 53.3 & $\mathrm{abc}$ & 33.8 & $\mathrm{~b}$ & 54.6 & $\mathrm{ab}$ \\
\hline Patton & 19.0 & defg & 20.9 & bcdefg & 44.6 & bcd \\
\hline Roane & 19.0 & efg & 28.0 & bcd & 43.0 & bcde \\
\hline Sisson & 34.4 & de & 20.9 & bcdefg & 25.1 & $\mathrm{f}$ \\
\hline Mean & 32.9 & $\ldots$ & 22.9 & $\ldots$ & 40.2 & $\ldots$ \\
\hline
\end{tabular}

${ }^{\mathrm{v}}$ Means were based on three repetitions of each cultivar at each site in each year. Each repetition was a hill plot planted with $3 \mathrm{~g}$ of seed spaced $0.46 \mathrm{~m}$ apart.

w Percentage of Stagonospora nodorum seed infestation was based on 100 seed from each plot at each location.

${ }^{\mathrm{x}}$ Effect of cultivar was significant $(P \leq 0.0001)$ using the $F$ test in a linear mixed model (with Satterthwaite approximation for degrees of freedom) for leaf and glume blotch severities and percent seed infested.

y Least squares means of diseased were rated visually on the last assessment date and were approximated using restricted maximum likelihood.

${ }^{\mathrm{z}}$ Groups were assigned based on pairwise comparisons of the cultivar means, based on standard error of mean differences determined in the mixed model. Means followed by the same letter are not significantly different at $P \leq 0.05$. 
cultivars varied in reaction between the inoculated and naturally infected field plots for the level of seed infestation (Tables 3 and 4).

Visual examinations revealed that seed presumed to be infested by $S$. nodorum from naturally infested plots in 2003 also were infested with $P$. tritici-repentis and $B$. sorokiniana. The incidence of seed infested by $P$. tritici-repentis was determined from both Wayne and Pickaway County sites. The greatest amount of seed infestation by $P$. tritici-repentis was on cv. Roane $(0.4 \%)$ (Table 5), but this fungus was not recovered from harvested seed of cvs. Patton, Patterson, or Sisson. Although $P$. tritici-repentis can be detected in seed samples, the low incidence of infestation did not allow for clear separation of the cultivars examined based on statistical tests.

The amount of $B$. sorokiniana infestation was negligible $(<3 \%)$ on seed from the Pickaway County site; therefore, only seed from the Wayne County site were analyzed. ANOVA indicated a statistical effect of cultivar in the amount of seed infested by $B$. sorokiniana. Bouillon had

Table 4. Mean Stagonospora leaf and glume blotch severities of the 13 cultivars planted in naturally infested plots in Wayne and Pickaway Counties 2003 and 2004

\begin{tabular}{|c|c|c|c|c|c|c|}
\hline \multirow[b]{2}{*}{ Cultivar $^{\mathrm{x}}$} & \multicolumn{2}{|c|}{ Leaf blotch ${ }^{v}$} & \multicolumn{2}{|c|}{ Glume blotch ${ }^{v}$} & \multicolumn{2}{|c|}{ Seed infestation ${ }^{w}$} \\
\hline & Mean ${ }^{y}$ & Group $^{z}$ & Mean $^{y}$ & Group $^{z}$ & Mean ${ }^{y}$ & Group $^{z}$ \\
\hline AGRA GR535 & 26.4 & de & 11.0 & $\mathrm{bc}$ & 30.7 & bcd \\
\hline Bouillon & 27.6 & de & 5.4 & $\mathrm{c}$ & 23.0 & $\mathrm{~cd}$ \\
\hline Bravo & 33.9 & $\mathrm{~cd}$ & 16.8 & $a b$ & 28.3 & bcd \\
\hline Coker 9025 & 48.6 & $a b$ & 11.7 & $\mathrm{bc}$ & 19.3 & $\mathrm{~d}$ \\
\hline Coker 9474 & 31.4 & de & 7.5 & $\mathrm{c}$ & 32.4 & $\mathrm{bc}$ \\
\hline Coker 9663 & 19.8 & $\mathrm{e}$ & 7.5 & $\mathrm{c}$ & 21.0 & $\mathrm{~cd}$ \\
\hline Freedom & 44.6 & bc & 7.6 & $\mathrm{c}$ & 20.7 & $\mathrm{~cd}$ \\
\hline Honey & 58.9 & $\mathrm{a}$ & 10.3 & bc & 23.3 & $\mathrm{~cd}$ \\
\hline Hopewell & 53.4 & $a b$ & 20.9 & $\mathrm{a}$ & 23.3 & $\mathrm{~cd}$ \\
\hline Patterson & 58.9 & $\mathrm{a}$ & 14.5 & $a b$ & 47.8 & $\mathrm{a}$ \\
\hline Patton & 25.6 & de & 9.1 & $\mathrm{bc}$ & 37.3 & $a b$ \\
\hline Roane & 22.6 & de & 5.6 & $\mathrm{c}$ & 28.4 & bcd \\
\hline Sisson & 44.8 & bc & 24.1 & $\mathrm{a}$ & 22.4 & $\mathrm{~cd}$ \\
\hline Mean & 38.2 & $\ldots$ & 11.7 & $\ldots$ & 27.5 & $\ldots$ \\
\hline
\end{tabular}

${ }^{\mathrm{v}}$ Means were based on four repetitions of each cultivar. Each repetition was a drill strip 8 rows by 6.1 m long.

${ }^{w}$ Means were based on 105 seed for each cultivar in each of four repetitions.

${ }^{x}$ Effect of cultivar was significant (leaf $P<0.0001$, glume $P=0.001$, seed $P=0.0003$ ) using the $F$ test in a linear mixed model (with Satterthwaite approximation for degrees of freedom).

${ }^{y}$ Least squares means of disease severities and percent seed infestation were approximated using restricted maximum likelihood.

${ }^{\mathrm{z}}$ Groups were assigned based on pairwise comparisons of the cultivar means, based on standard error of mean differences determined in the mixed model. Means followed by the same letter are not significantly different at $P \leq 0.05$.

Table 5. Percentage of seed infested with Pyrenophora tritici-repentis and Bipolaris sorokiniana of the 13 cultivars harvested from naturally infested field plots in Pickaway and Wayne Counties in 2004

\begin{tabular}{lcccc}
\hline & P. tritici-repentis $^{\mathbf{w}}$ & & \multicolumn{2}{c}{ B. sorokiniana $^{\mathbf{x}}$} \\
\cline { 2 - 3 } Cultivar & Mean & & Mean $^{\mathbf{y}}$ & Group $^{\mathbf{z}}$ \\
\hline AGRA GR535 & 0.1 & 4.7 & $\mathrm{bcd}$ \\
Bouillon & 0.1 & 8.8 & $\mathrm{a}$ \\
Bravo & 0.1 & 3.3 & $\mathrm{~cd}$ \\
Coker 9025 & 0.3 & & $\mathrm{ab}$ \\
Coker 9474 & 0.1 & & $\mathrm{~cd}$ \\
Coker 9663 & 0.3 & & 8.5 & $\mathrm{a}$ \\
Freedom & 0.1 & 2.0 & $\mathrm{~d}$ \\
Honey & 0.1 & 2.0 & $\mathrm{~d}$ \\
Hopewell & 0.1 & 2.0 & $\mathrm{~d}$ \\
Patterson & 0 & 3.3 & $\mathrm{~cd}$ \\
Patton & 0 & 1.5 & $\mathrm{~d}$ \\
Roane & 0.4 & 5.3 & $\mathrm{bc}$ \\
Sisson & 0 & 3.5 & $\mathrm{~cd}$ \\
Mean & 0.1 & & $\ldots$ \\
\hline
\end{tabular}

${ }^{\mathrm{v}}$ Means are based on were based on 105 seeds from each of four repetitions of each cultivar at each site. Each repetition was a drill strip seven rows by $6.1 \mathrm{~m}$ long.

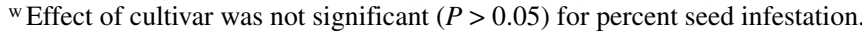

${ }^{\mathrm{x}}$ Effect of cultivar was significant $(P<0.0001)$ using the $F$ test in a linear mixed model (with Satterthwaite approximation for degrees of freedom). Only seed from Wayne site examined.

${ }^{y}$ Least squares means were approximated using restricted maximum likelihood.

${ }^{\mathrm{z}}$ Groups were assigned based on pairwise comparisons of the cultivar means, based on standard error of mean differences determined in the mixed model. Means followed by the same letter are not significantly different at $P \leq 0.05$.
$8.8 \%$ seed infested whereas Patton had the least seed infestation, $1.5 \%$ (Table 5). Infestation of these pathogens was not surprising because leaf samples from naturally infested plots collected in 2003 had a higher prevalence of these pathogens $(38 \%)$ than the previous year $(20 \%)$.

Correlation between greenhouse and field reactions. Mean leaf blotch severity values from the greenhouse and field plots all were correlated significantly according to calculated Pearson's correlation, with the highest correlation between the inoculated and naturally infested field plots $(\mathrm{r}=$ 0.91, $P=<0.0001$ ) (Table 6). Cultivar mean glume blotch severities obtained in the greenhouse were marginally significantly correlated with the inoculated field plot, but not with the naturally infested field plot $(\mathrm{r}=0.54, P=0.55)$.

Greenhouse leaf blotch severities were moderately correlated with greenhouse glume blotch severities $(\mathrm{r}=0.56, P=$ 0.046). Mean leaf blotch severities from inoculated plots were moderately correlated with glume blotch severities from inoculated plots $(\mathrm{r}=0.65, P=0.008)$. In the naturally infested field plots, mean leaf blotch severities were not significantly correlated with glume blotch severities $(\mathrm{r}=$ $0.52, P=0.07$ ).

Correlation between glume blotch reaction and seed infestation. Pearson's correlation between the least squares mean estimates of disease severities and percentages of seed infested were calculated. Mean cultivar glume blotch severities from the inoculated field plot were significantly correlated with the percentage of $S$. nodorum-infested seed $(\mathrm{r}=0.57, P=$ 0.028 ), but mean cultivar glume blotch severities were not correlated with percentage of $S$. nodorum-infested seed in the naturally infested field plot. The percentage of infested seed from the inoculated plots had a moderately high correlation with the percentage of infested seed from naturally infested plots $(\mathrm{r}=0.76, P=$ $0.003)$

\section{DISCUSSION}

Inoculation with $S$. nodorum pycnidiospores in the greenhouse produced only moderate Stagonospora leaf blotch severities; however, significant statistical differences were detected among reactions of the soft red winter wheat cultivars. The low severities of Coker 9663 and Roane compared with the susceptible check, Patterson, indicated that these cultivars had moderately resistant reactions. In inoculated field plots, Coker 9663 consistently had a moderately resistant reaction. The fact that Roane had higher leaf blotch severities, similar to those of Bravo and Sisson, when tested in the inoculated field plot indicated that, under very high disease pressure, Roane may exhibit less resistance than expected. By comparison, the Ohio State University advanced breeding line, 
OH708, expressed a moderately resistant reaction in the inoculated field plot. These results indicate that Coker 9663 and, potentially, $\mathrm{OH} 708$ have moderate resistance to $S$. nodorum, and that resistance reactions in the greenhouse and inoculated field plots consistently distinguished resistant from susceptible genotypes.

Difficulty in assessing cultivar reactions to Stagonospora leaf blotch has been observed in other areas of the world due to competition from other leaf pathogens (5). Both $P$. tritici-repentis and B. sorokiniana have been isolated from wheat flag leaves collected in most wheat-growing regions of Ohio (8), and leaf sampling indicated their presence in the naturally infested field plots. In some cases, individual flag leaves were observed to have spores of $S$. nodorum, $B$. sorokiniana, and $P$. triticirepentis within the same lesion (8). Due to similarity between lesion types produced by $P$. tritici-repentis and $S$. nodorum (5), confusion of lesion types could cause an observer to classify the reaction of this cultivar as moderately susceptible. For example, it is likely that the higher leaf blotch severities of Coker 9663 in the naturally infested plots was influenced by mixed infections of $S$. nodorum, B. sorokiniana, and/or $P$. tritici-repentis, regardless of attempts to estimate severities of Stagonospora leaf blotch alone. Nevertheless, it appears that Coker 9663 had a moderately resistant reaction based on multiple year and multiple location testing.

$S$. nodorum seed infestation was not determined after greenhouse inoculations because of higher amounts of disease which apparently caused floret sterility. In inoculated and naturally infested field plots, the lowest observed seed infestation by $S$. nodorum was $19 \%$. The moderately high percentage of seed infestation may be explained by an increase in inoculum during several wet periods during the later stages of seed fill and maturation, which occurred after glume blotch severities were recorded. This percentage of seed infestation could initiate epidemics if this seed were planted in the field and weather conditions favored disease spread (26). The correlation between glume blotch severity

Table 6. Pearson's correlation coefficients for the relationship between mean cultivar Stagonospora blotch assessments in the greenhouse and field plots ${ }^{\mathrm{x}}$

\begin{tabular}{lccccc}
\hline & \multicolumn{2}{c}{ IFP } & & \multicolumn{2}{c}{ NIFP } \\
\cline { 2 - 3 } \cline { 5 - 6 } Blotch $^{\mathbf{y}}$ & $\mathbf{r}^{\mathbf{z}}$ & $\boldsymbol{P}$ value & & $\mathbf{r}$ & $\boldsymbol{P}$ value \\
\hline Leaf blotch & & & & & \\
GH & 0.78 & 0.002 & & 0.70 & 0.008 \\
NIFP & 0.91 & $<0.0001$ & & $\ldots$ & $\ldots$ \\
Glume blotch & & & & \\
GH & 0.54 & 0.055 & & -0.08 & $\mathrm{~ns}$ \\
NIFP & 0.13 & $\mathrm{~ns}$ & $\ldots$ & $\ldots$ \\
\hline
\end{tabular}

${ }^{\mathrm{x}}$ IFP $=$ inoculated field plot, NIFP $=$ naturally infested field plot, and $\mathrm{ns}=$ not significant.

${ }^{y}$ Leaf and glume blotch assessments were visual estimations of percent leaf area affected. Greenhouse (GH) assessments were taken 28 days post inoculation. Field plot assessments were the last assessment before senescence.

${ }^{\text {z }}$ Pearson's correlation coefficients were based on mean cultivar disease assessments in each study.
LITERATURE CITED

1. Beuerlein, J., Lipps, P. E., and Minyo, R. J., Jr. 2000. Ohio wheat performance trials, 2000. The Ohio State University, Ohio State University Extension, HCS Ser. 228.

2. Beuerlein, J., Lipps, P. E., and Minyo, R. J., Jr. 2001. Ohio wheat performance trials, 2001 The Ohio State University, Ohio State University Extension, HCS Ser. 228.

3. Beuerlein, J., Lipps, P. E., and Minyo, R. J., Jr. 2003. Ohio wheat performance trials, 2003. The Ohio State University, Ohio State University Extension, HCS Ser. 228.

4. Beuerlein, J., Lipps, P. E., and Minyo, R. J., Jr. 2004. Ohio wheat performance trials, 2004 The Ohio State University, Ohio State University Extension, HCS Ser. 228.

5. Bhathal, J. S., Loughman, R., and Speijers, J. 2003. Yield reduction in wheat in relation to leaf disease from yellow (tan) spot and Septoria nodorum blotch. Eur. J. Plant Pathol. 109:435-443.

6. Cunfer, B. M., Strocksbury, D. E., and Johnson, J. W. 1988. Components of partial resistance to Leptosphaeria nodorum among seven soft red winter wheats. Euphytica 37:129-140.

7. Du, C. G., Nelson, L. R., and McDaniel, M. E. 1999. Partial resistance to Stagonospora nodorum in wheat. Pages 160-162 in: Septoria and Stagonospora Diseases of Cereals: A Compilation of Global Research. CIMMYT, Mexico D. F., Mexico. (Published online)

8. Engle, J. S. 2005. Pathogenic characterization, distribution in Ohio and wheat genotype reaction to Stagonospora nodorum and Pyrenophora tritici-repentis. Ph.D. dissertation, The Ohio State University, Columbus.

9. Eyal, Z., Scharen, A. L., Prescott, J. M., and van Ginkel, M. 1987. The Septoria Diseases of Wheat: Concepts and Methods of Disease Management. CIMMYT, Mexico D.F., Mexico.

10. Fraser, D. E., Murphy, J. P., and Leath, S 1999. Comparison of methods of screening for Stagonospora nodorum resistance in winter wheat. Pages 163-166 in: Septoria and Stagonospora Diseases of Cereals: A Compilation of Global Research. CIMMYT, Mexico D. F., Mexico. (Published online)

11. Gilbert, J., and Tekauz, A. 1993. Reaction of Canadian spring wheats to Septoria nodorum and the relationship between disease severity and yield components. Plant Dis. 77:398-402.

12. Krupinsky, J. M. 1997. Aggressiveness of Stagonospora nodorum isolates from perennial grasses on wheat. Plant Dis. 81:1032-1036.

13. Krupinsky, J. M., Schillinger, J. A., and Scharen, A. L. 1972. Resistance in wheats to Septoria nodorum. Crop Sci. 12:528-530.

14. Large, E. C. 1954. Growth stages in cereals Illustration of the Feekes scale. Plant Pathol. 3:128-129.

15. Loughman, R., and Thomas G. J. 1992. Fungicide and cultivar control of Septoria diseases of wheat. Crop Prot. 11:349-354.

16. Loughman, R., Wilson, R. E., and Thomas, G. J. 1994. The influence of disease complexes involving Leptosphaeria (Septoria) nodorum on detection of resistance to three leaf spot diseases in wheat. Euphytica 72:31-42.

17. Luke, H. H., Pfahler, P. L., and Barnett, R. D. 1983. Control of Septoria nodorum on wheat with crop rotation and seed treatment. Plant Dis. 67:949-951.

18. Manandhar, J. B., and Cunfer, B. M. 1991. An improved selective medium for the assay of Septoria nodorum from wheat seed. Phytopathology 81:771-7773.

19. Milus, E. A., and Chalkley, D. B. 1997. Effect of previous crop, seedborne inoculum, and fungicides on development of Stagonospora blotch. Plant Dis. 81:1279-1283.

20. Mullaney, E. J., Martin, J. M., and Scharen, A. L. 1982. Generation mean analysis to identify 
and partition the components of genetic resistance to Septoria nodorum in wheat. Euphytica 31:539-545.

21. Nelson, L. R., and Gates, C. E. 1982. Genetics of host plant resistance of wheat to Septoria nodorum. Crop Sci. 22:771-773.

22. Nelson, L. R., Morey, D. D., and Brown, A. R. 1974. Wheat cultivar responses to severe glume blotch in Georgia. Plant Dis. Rep. 58:21-23.

23. Roth, G., DeWolf, E. D., Johnson, D., and Heinbaugh, S. 2002 Pennsylvania winter wheat and barley performance test. Pennsylvania State University. Pennsylvania State University Extension. (Published online)

24. Scharen, A. L. 1999. Biology of the Septoria/Stagonospora pathogens: An overview. Pages 19-22 in: Septoria and Stagonospora
Diseases of Cereals: A Compilation of Global Research. CIMMYT, Mexico D. F., Mexico. (Published online)

25. Scharen, A. L., and Eyal, Z. 1983. Analysis of symptoms on spring and winter wheat cultivars inoculated with different isolates of Septoria nodorum. Phytopathology 73:143-147.

26. Shah, D. A., and Bergstrom, G. C. 1999. Epidemiology of seedborne Stagonospora nodorum: A case study on New York winter wheat. Pages 102-104 in: Septoria and Stagonospora Diseases of Cereals: A Compilation of Global Research. CIMMYT, Mexico D. F., Mexico. (Published online)

27. Shah, D. A., and Madden, L. V. 2004. Nonparametric analysis of ordinal data in designed factorial experiments. Phytopathology 94:3343.
28. Shaner, G., and Buechley, G. 1995. Epidemiology of leaf blotch of soft red winter whea caused by Septoria tritici and Stagonospora nodorum. Plant Dis. 79:928-938.

29. Tuite, J. 1969. Plant Pathological Methods: Fungi and Bacteria. Burgess Publishing Company, Minneapolis, MN.

30. Verreet, J. A., and Hoffmann, G. M. 1990. A biologically oriented threshold decision model for control of epidemics of Septoria nodorum in wheat. Plant Dis. 74:731-738.

31. Walker, S. L., Leath, S., and Murphy, J. P. 1999. Comparison of greenhouse and field levels of resistance to Stagonospora nodorum. Pages 170-172 in: Septoria and Stagonospora Diseases of Cereals: A Compilation of Global Research. CIMMYT, Mexico D. F., Mexico. (Published online) 